\title{
APLIKASI SISTEM INFORMASI AKADEMIK PADA SD INTEGRAL HIDAYATULLAH DEPOK BERBASIS JAVA
}

\author{
Aldi Hidayat $^{1)}$, Bondan Dwi Hatmoko ${ }^{2)}$, Luh Putu Widya Adnyani ${ }^{3)}$ \\ ${ }^{1}$ Informatika, Universitas Indraprasta PGRI \\ ${ }^{2}$ Informatika, Universitas Indraprasta PGRI \\ ${ }^{3}$ Informatika, Universitas Indraprasta PGRI \\ 12aldihidayat53@gmail.com
}

\begin{abstract}
Academic Information System is a system that provides information services in the form of academic data. The existence of this information system is important. In this case, SD Integral Hidayatullah is used as a place of research, because the academic information system in the school has not been well managed so that it often makes it difficult to carry out existing academic activities, such as processing student data, processing teacher data, processing student grades., processing student absences, and processing subject data. The purpose of this study was to provide convenience when processing student and teacher data, facilitate the processing of student grades, minimize errors in recording student data, and improve student data security so that student data security is more secure. And from the research objectives, several uses are generated, consisting of practical and academic uses. The research method used in this research is based on the applied method. Meanwhile, the system development uses the waterfall model. The software used is: windows 7, netbeans 8.2, and xampp. The result of this research is a program called: an academic information system application at SD Integral Hidayatullah Depok based on Java, a program designed to facilitate academic activities at SD Integral Hidayatullah Depok.
\end{abstract}

Keywords: applications, information systems, academic, java

\begin{abstract}
Abstrak
Sistem Informasi Akademik merupakan suatu sistem yang meberikan layanan informasi yang berupa data akademik. Keberadaan sistem informasi ini penting. Dalam hal ini, SD Integral Hidayatullah dijadikan sebagai tempat penelitian, karena sistem informasi akademik yang ada di sekolah tersebut belum terkelola dengan baik sehingga seringkali mempersulit dalam pelaksanaan aktifitas-aktifitas akademik yang ada, seperti proses pengolahan data siswa, pengolahan data guru, pengolahan nilai siswa, pengolahan absen siswa, dan pengolahan data mata pelajaran. Tujuan penelitian ini adalah untuk memberikan kemudahan pada saat proses pengolahan data siswa dan guru, mempermudah dalam pengolahan nilai siswa, meminimalisir kesalahan dalam pencatatan data siswa, dan meningkatkan keamanan data siswa sehingga keamanan data siswa lebih terjamin. Dan dari tujuan penelitian tersebut dihasilkan beberapa kegunaan yang terdiri dari kegunaan praktis dan akademis. Metode penelitian yang digunakan dalam penelitian ini adalah berdasarkan metode terapan. Sedangkan pengembangan sistemnya menggunakan model waterfall. Perangkat lunak yang digunakan adalah : windows 7, netbeans 8.2, dan xampp. Hasil dari penelitan ini adalah sebuah program bernama : aplikasi sistem informasi akademik pada SD Integral Hidayatullah Depok Berbasis Java, sebuah program yang dibuat untuk mempermudah aktifitas akademik di SD Integral Hidayatullah Depok.
\end{abstract}

Keywords: aplikasi, sistem informasi, akademik, java

\section{PENDAHULUAN}

Semakin pesatnya teknologi saat ini, dibutuhkan sarana dalam bidang informasi dan pengolahan data yang cepat sesuai waktu yang diharapkan oleh berbagai bidang kegiatan usaha seperti industri, perdagangan, pendidikan, perusahaan, sains dan ilmu pengetahuan lainnya. Untuk itu diperlukan teknologi yang mampu menyajikan informasi dan pengolahan data yang seacara cepat dan akurat.

Berdasarkan pengamatan di lapangan proses akademik di SD Integral Hidayatullah Depok bersifat manual. Sekolah sudah menyediakan komputer tapi belum difungsikan secara optimal.

Terdapat beberapa kendala yang didapat dari pengamatan penulis tentang sistem akademik, yaitu susahnya mendapatkan laporan secara rinci untuk mengolah pendataan. Selain itu, kurang terjaminnya keamanan data sebab penyimpanan data informasi laporan yang baik merupakan faktor terpenting dalam proses akademik khususnya di sekolah.

Dalam mengolah dan mengumpulkan data, SD Integral Hidayatullah menggunakan Microsoft Word dan Microsoft Excel. Hal tersebut tidak mampu mencegah terjadinya pengulangan data 
yang dibukukan, termasuk pendataan pada sistem informasi akademik. Pengulangan data menyebabkan kurang efisien dalam pembukuan dan sering terjadi kesalahan pada hubungan antara data satu dengan data yang lainnya. Seiring dengan berjalannya waktu maka diperlukan cara yang lebih cepat,tepat,akurat dan efisien dalam mengolah data sistem informasi akademik yang terkini sehingga dibutuhkan suatu program khusus yang dapat mendukungnya.

aplikasi adalah suatu subkelas perangkat lunak komputer yang memanfaatkan kemampuan komputer langsung untuk melakukan suatu tugas yang diinginkan pengguna. Biasanya dibandingkan dengan perangkat lunak sistem yang mengintegrasikan berbagai kemampuan komputer, tapi tidak secara langsung menerapkan kemampuan tersebut untuk mengerjakan suatu tugas yang menguntungkan pengguna [1].

Sistem informasi adalah cara-cara yang diorganisasi untuk mengumpulakan, memasukkan, mengolah, dan menyimpan data dan cara-cara yang diorganisasi untuk menyimpan, mengelola, mengendalikan dan melaporkan informasi sedemikian rupa sehingga sebuah organisasi dapat mencapai tujuan yang telah ditetapkan [2].

Informasi merupakan salah satu kebutuhan di dalam suatu instansi, perusahaan,organisasi, lembaga serta lingkungan yang berada di luar sistem. Perubahan dan dinamika masyarakat yang semakin cepat seiring dengan perkembangan jaman dan teknologi memerlukan kualitas informasi yang akurat, cepat, dan tepat [3].

sistem informasi dapat didefinisikan sebagai kumpulan komponen yang digunakan untuk mengolah data sehingga menghasilkan suatu informasi yang dapat digunakan untuk pengambilan keputusan [4].

Aplikasi sistem informasi merupakan cara yang diambil berdasarkan hasil analisa sistem kemudian dibuat rancangan sistemnya, meliputi: Diagram Konteks, Data Flow Diagram, Entity Relationship Diagram (ERD), Relasi antar File, Struktur File, Struktur Program, Struktur Menu, Format Masukan dan Format Luaran [5].

Akademik adalah seluruh lembaga pendidikan formal baik pendidikan anak usia dini, pendidikan dasar, pendidikan menengah, pendidikan kejuruan maupun perguruan tinggi yang menyelenggarakan pendidikan vokasi dalam satu cabang atau sebagian cabang ilmu pengetahuan, teknologi, dan/atau seni tertentu [6].

\section{METODELOGI PENELITIAN}

Metode penelitian merupakan suatu metode atau cara yang relevan dan efektif untuk memperoleh suatu data dengan tujuan yang ingin dicapai. metode penelitian adalah cara ilmiah untuk mendapatkan data dengan tujuan dan kegunaan tertentu [7]. Metode penelitian yang digunakan dalam penelitian ini adalah metode penelitian terapan. Penelitian terapan merupakan kegiatan riset yang memuat prototipe riset dan pengembangan atau rekomendasi kebijakan, proposal, konsep, model, dan indeks yang meliputi validasi komponen/subsistem dalam lingkungan yang relevan, dan hasilnya disampaikan dalam bentuk laporan kegiatan yang komprehensif.

Metode pengumpulan data yang dilakukan oleh penulis untuk mendapatkan data-data serta informasi untuk mendukung penyempurnaan hasil dari penelitian ini antara lain:

1) Observasi (Pengamatan Langsung)

Yaitu metode untuk mendapatkan data dengan melakukan pengamatan langsung, pencatatan dan pengumpulan data-data yang dilakukan pada SD Integral Hidayatullah Depok

2) Interview (Wawancara)

Penulis juga melakukan metode wawancara dalam pengumpulan data yang diperlukan untuk menyusun skripsi ini. Metode wawancara ini penulis tunjukan kepada orang-orang yang berkecimpung langsung maupun tidak langsung dalam proses pengelolaan pada SD Integral Hidayatullah Depok, guna mencari penjelasan pada saat observasi.

3) Metode Perpustakaan (Studi Literatur)

Terkait pengumpulan data yang bersumber dari buku-buku serta catatan selama perkuliahan, atau buku penunjang lainnya sehingga data tersebut dapat diambil berdasarkan kaitan topik yang tersusun sebagai penunjang.

4) Dokumentasi

Penulis melakukan pengumpulan data dengan cara melihat dan mencatat data yang ada pada dokumen atau arsip dari SD Integral Hidayatullah Depok. Serta melihat proses berjalan nya sistem berjalan yang ada pada SD Integral Hidayatullah Depok. Sehingga penulis mendapatkan informasi dari metodemetode yang sudah dilakukan sebelumnya.

5) Studi Pustaka 
Studi pustaka dilakukan dengan mencari informasi atau data melalui buku-buku, artikel dan internet sebagai referensi yang berkaitan dengan penelitian.

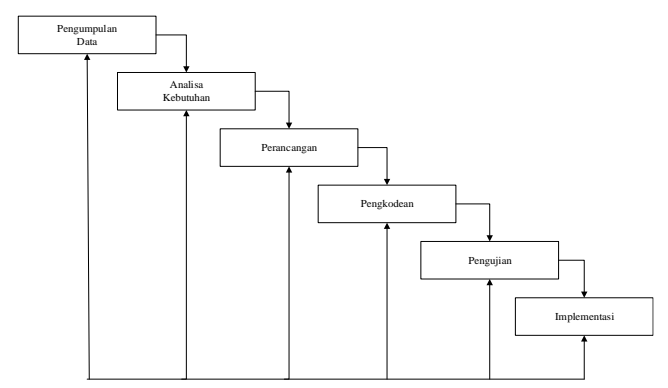

Gambar 1. Model Air Terjun (Waterfall)

1. Pengumpulan Data

Dalam tahap ini penulis melakukan pengumpulan kebutuhan seluruh elemen seperti data-data yang digunakan. Dimana elemen-elemen itu dapat menunjang dalam pengembangan aplikasi klinik.

2. Analisa Kebutuhan

Tahapan analisis kebutuhan dilaksanakan dengan menganalisa keperluan pengguna, analisa software dan hardware yang diperlukan untuk pengembangan sistem serta keperluan lain dalam membuat database. Analisis kebutuhan hardware pada sistem ini yaitu laptop dengan spesifikasi sebagai berikut Acer Aspire E1-471, processor Intel Core i3-2348M, 2,30GHz Ram 6GB. Analisis kebutuhan software yang digunakan dalam pembuatan sistem ini yaitu Sistem Operasi Windows 7, XAMPP, MySQL dan Netbeans.

3. Perancangan

Langkah selanjutnya yaitu mendesain sistem. Tahapan ini dibuat sebelum tahap pengodean. Tahapan ini bertujuan untuk memberikan gambaran tentang apa yang akan dikerjakan dan bagaimana tampilannya. Tahapan ini akan menghasilkan perancangan Diagram Alir Data (DAD), Entity Relationship Diagram (ERD), Normalisasi dan perancangan antar muka.

4. Pengkodean

Pada tahapan ini dilakukan penulisan kode program yang telah dibuat ke dalam bentuk perintah-perintah yang dimengerti komputer dengan menggunakan bahasa pemrograman java dan database MySQL. Tahapan ini sangat penting dalam pengembangan suatu sistem.
5. Pengujian

Tahapan pengujian dilakukan guna memastikan bahwa sistem yang dibuat sudah sesuai dengan desainnya dan semua fungsi dapat dipergunakan dengan baik tanpa ada kesalahan.

6. Implementasi

Tahapan ini adalah tahap terakhir pada metode waterfall. Sistem yang sudah jadi akan diimplementasikan lalu dilakukan pemeliharaan untuk mengetahui berbagai error yang tidak ditemukan pada tahap-tahap terdahulu, perbaikan sistem, serta pemeliharaan sistem.

\section{HASIL DAN PEMBAHASAN \\ Diagram Alir Data/Diagram Flow Data (DAD/DFD)}

DFD (Data Flow Diagram) adalah program yang menggunakan notas-notasi seperti lingkaran dan anak panah untuk mnggambarkan arus data dari sistem.

Diagram alir data merupakan model dari sistem untuk menggambarkan pembagian sistem ke modul yang lebih besar [8]. Jadi dapat disimpulkan bahwa diagram alir data merupakan model dari sistem perangkat lunak, menggambarkan pembagian sistem ke modul yang lebih besar.tingkat atau level Diagaram Alir Data (DAD) terdiri dari:

1) Diagram Konteks

Merupakan diagram yang ditingkatkan paling tinggi, yang terdiri dari suatu proses dan menggambarkan ruang lingkup sistem.

2) Diagram Nol

Merupakan diagram konteks yang berkembang di mana di dalamnya menggambarkan proses utama dari DAD yang sedang dikembangkan.

3) Diagram Rinci

Merupakan diagram paling bawah, yang merupakan penguraian dari proses yang ada pada diagram nol. 


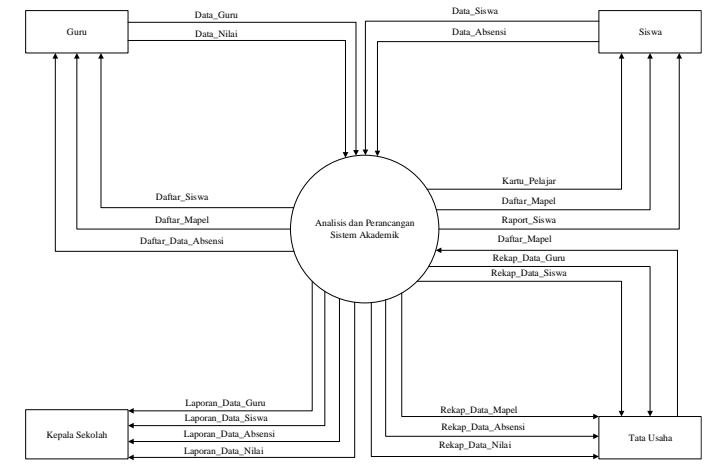

Gambar 2. Diagram Alir Data (DAD) Sistem yang Diusulkan

\section{Normalisasi}

Normalisasi adalah sebuah teknik yang menghasilkan suatu kumpulan relasi dengan property yang diinginkan dengan memberikan suatu kebutuhan data pada perusahaan [9].

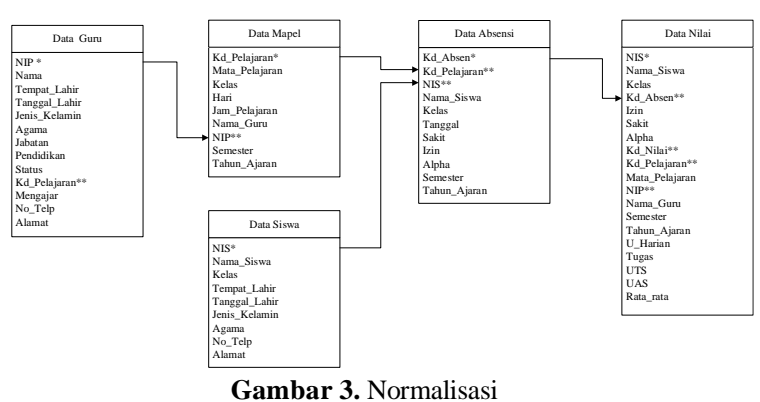

\section{Entity Relationship Diagram (ERD)}

ERD (Entity Relationship Diagram) adalah pemodelan awal basis data yang dikembangkan berdasarkan teori himpunan dalam bidang matematika. ERD digunakan untuk pemodelan basis data relasional [10].

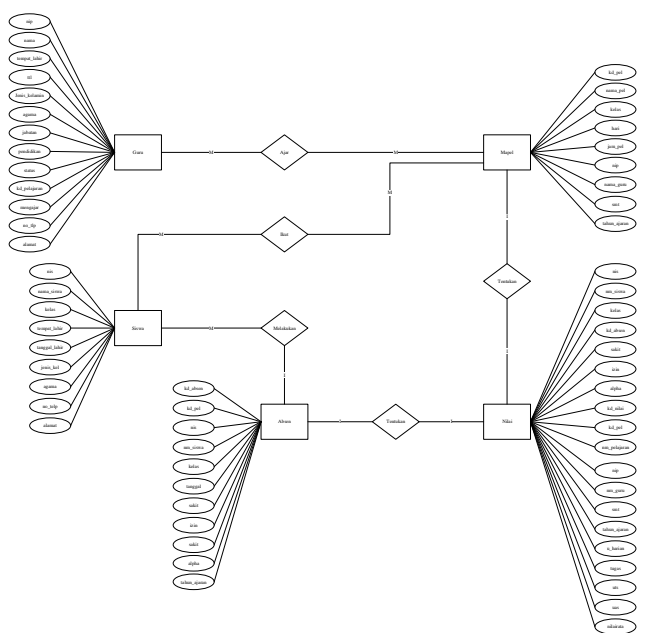

Gambar 4. Entity Relationship Diagram (ERD)

\section{Struktur Tampilan Menu Aplikasi \\ 1. Tampilan Layar}

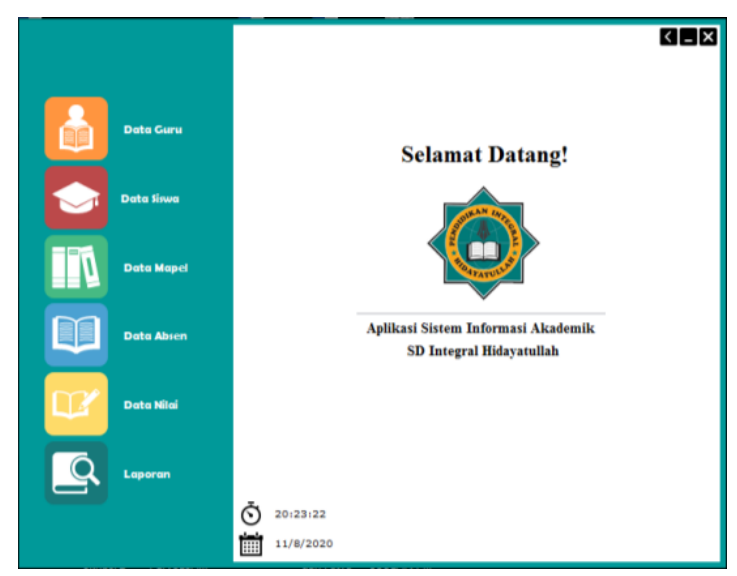

Gambar 5. Tampilan Menu Utama

Tampilan di atas ini adalah tampilan Menu Utama setelah melakukan login. Di tampilan tersebut terdapat beberapa menu seperti menu data guru, data siswa, data mapel, data absensi siswa, laporan.

Berikut ini merupakan penjelasan mengenai fitur-fitur yang ada pada aplikasi akademik. Fitur-fitur tersebut antara lain sebagai berikut:

1. Mampu mengolah sistem aplikasi pada akademik yang mudah dimengerti dan dapat dimanfaatkan oleh bagian tata usaha .

2. Mampu membuat sistem yang bisa mengerjakan proses transaksi secara terintegrasi untuk meningkatkan kualitas pelayanan dan meningkatkan kinerja.

3. Mampu menampilkan informasi data-data secara detail dan konkrit, sehingga pihak bagian tata usaha dapat dengan mudah mengevaluasi.

\section{Perancangan Input}

Perancangan input merupakan rancangan yang menggambarkan form input suatu data pada proses administrasi. Berikut ini merupakan bagian input data pada aplikasi akademik.

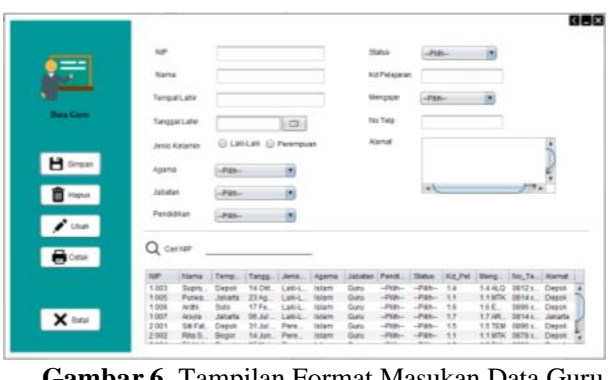


Tampilan di atas merupakan tampilan masukan data guru. Tampilan ini memiliki beberapa tombol yang terdiri dari tombol simpan untuk menyimpan data yang telah dimasukan, hapus untuk menghapus data, ubah untuk mengubah data, cetak untuk mencetak data, batal untuk mereset data yang akan diinput, dan cari untuk mencari data tertentu berdasarkan nip.

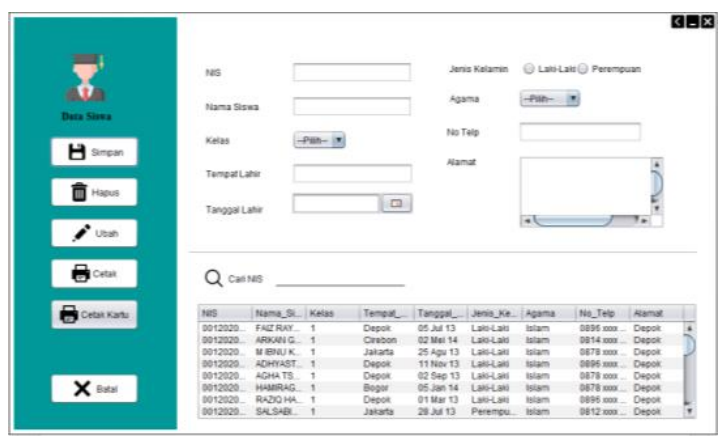

Gambar 7. Tampilan Format Masukan Data Siswa

Tampilan di atas merupakan tampilan masukan data siswa. Tampilan ini memiliki beberapa tombol yang terdiri dari tombol simpan untuk menyimpan data yang telah dimasukkan, hapus untuk menghapus data, ubah untuk mengubah data, cetak untuk mencetak data, batal untuk mereset data dari teks box perbaharui untuk mengubah data siswa, dan cari untuk mencari data tertentu berdasarkan nis.

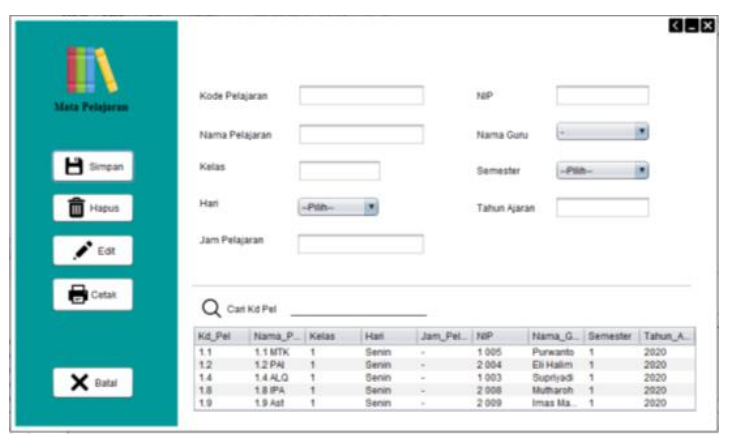

Gambar 8. Tampilan Format Masukan Data Mapel

Tampilan di atas merupakan tampilan masukan data mata pelajaran. Tampilan ini memiliki beberapa tombol yang terdiri dari tombol simpan untuk menyimpan data yang telah dimasukkan, hapus untuk menghapus data, ubah untuk mengubah data, cetak untuk mencetak mata pelajaran, batal untuk mereset teks box agar kosong kembali, dan cari untuk mencari data tertentu berdasarkan mapel

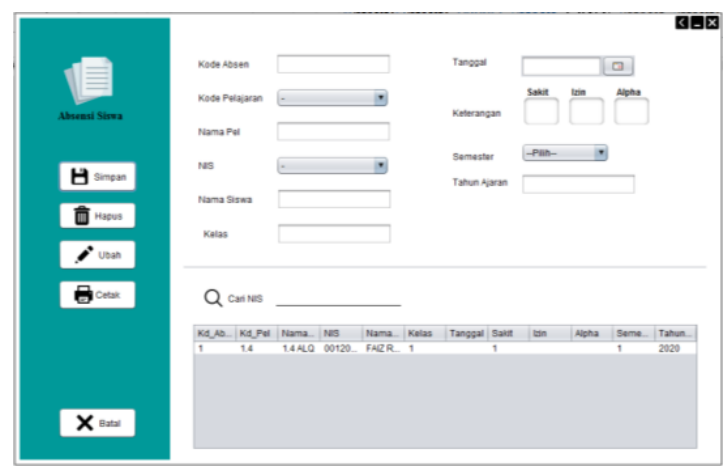

Gambar 9. Tampilan Format Masukan Data Absensi Siswa

Tampilan di atas merupakan tampilan masukan data absensi siswa. Tampilan ini memiliki beberapa tombol yang terdiri dari

tombol simpan untuk menyimpan data yang telah dimasukkan, hapus untuk menghapus data, ubah untuk mengubah data dan batal untuk mereset teks box agar kosong kembali, cetak untuk mencetak mata pelajaran dan cari untuk mencari data tertentu berdasarkan $\mathrm{kd}$ absen.

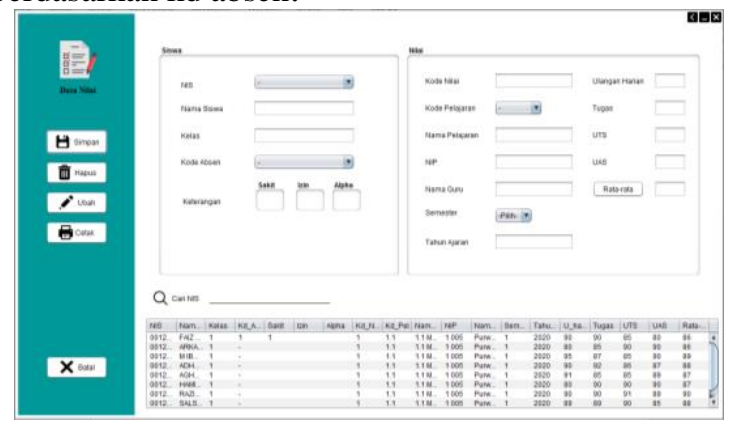

Gambar 10. Tampilan Format Masukan Data Nilai

Tampilan di atas merupakan tampilan masukan data nilai. Tampilan ini memiliki beberapa tombol yang terdiri dari tombol simpan untuk menyimpan data yang telah dimasukkan, hapus untuk menghapus data, ubah untuk mengubah data dan batal untuk mereset teks box agar kosong kembali cetak untuk mencetak data, teks box pencarian untuk mencari siswa berdasarkan nis, dan tombol rata-rata untuk menghitung total nilai rata-rata yang diperoleh siswa.

\section{Perancangan Output}

Perancangan output atau keluaran merupakan hal yang tidak dapat diabaikan, karena keluaran yang dihasilkan harus memudahkan bagi setiap unsur manusia yang membutuhkan. 


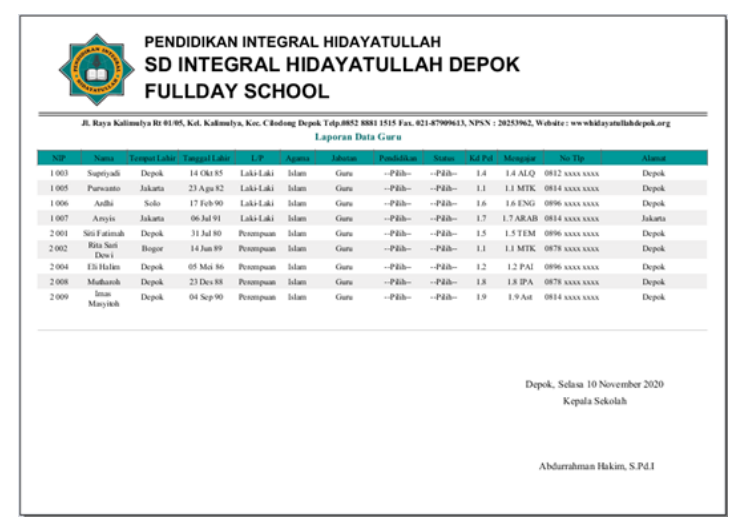

Gambar 11. Tampilan Format Laporan Data Guru

Laporan data guru muncul saat user memasukan data guru lalu mengklik tombol cetak pada tampilan data guru, maka akan keluar tampilan laporan data guru.

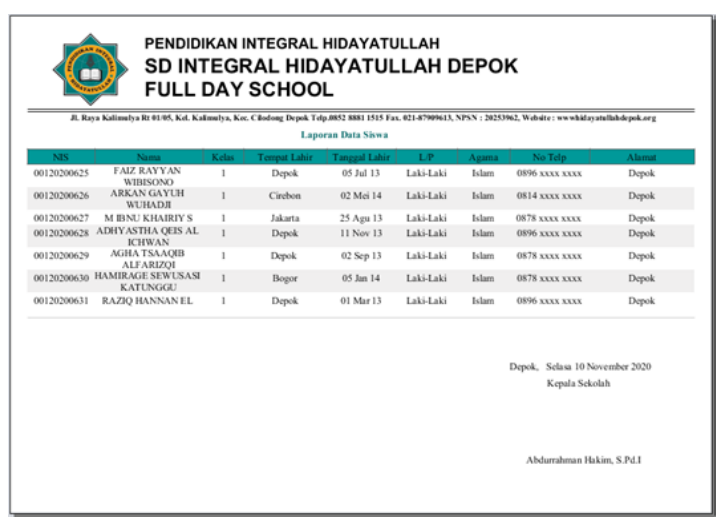

Gambar 12. Tampilan Format Laporan Data Siswa

Laporan data siswa muncul saat user memasukan data siswa lalu mengklik tombol cetak pada tampilan data siswa, maka akan keluar tampilan laporan data siswa.

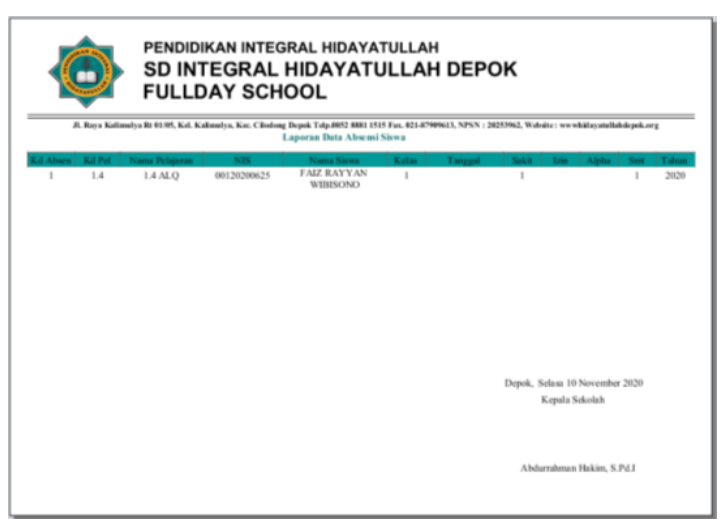

Gambar 13. Tampilan Format

Laporan Data Absensi Siswa

Laporan data absensi siswa muncul saat user memasukan data absensi siswa lalu mengklik tombol cetak pada tampilan data absensi siswa, maka akan keluar tampilan laporan data absensi siswa.

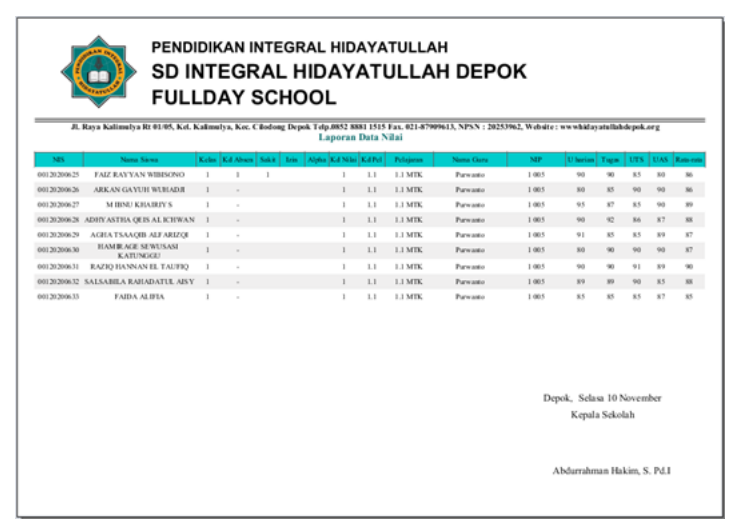

Gambar 14. Tampilan Format Laporan Data Nilai

Laporan data nilai muncul saat user memasukan data nilai lalu mengklik tombol cetak pada tampilan data nilai, maka akan keluar tampilan laporan data nilai.

\section{SIMPULAN DAN SARAN \\ Simpulan}

Berdasarkan hasil penelitian yang penulis lakukan pada SD Integral Hidayatullah Depok, serta dari pembahasan pada bab-bab sebelumnya, maka penulis dapat menarik kesimpulan sebagai berikut :

1. Dengan adanya Aplikasi Sistem Informasi Akademik, penginputan dan pengolahan data akademik dapat dilakukan secara komputerisasi, maka sistem akademik pada SD Integral Hidayatullah Depok lebih efektif dan efisien, karena penginputan dan pengolahan data tidak dilakukan secara manual lagi.

2. Penginputan dan pengolahan data tidak lagi dilakukan secara manual, karena penginputan dan pengolahan data tersebut dapat dilakukan dengan Aplikasi Sistem Informasi Akademik, proses penginputan daan pengolahan data lebih cepat dan terkonsep.

3. Staf Tata Usaha dengan mudah menginput atau mengolah data akademik. Sehingga menjadi lebih cepat, tepat, dan lebih efisien. 
Dengan sistem yang dibuat, maka demi tercapainya tujuan dan sasaran dengan yang diharapkan, maka saran yang diberikan sebagai berikut :

1. Aplikasi Sistem Informasi Akademik pada SD Integral Hidayatullah Depok harus didukung oleh sistem yang disiplin dan peraturan yang baik sesuai ketetapan bersama agar dapat berjalan dengan baik.

2. Aplikasi Sistem Informasi Akademik pada SD Integral Hidayatullah Depok dapat dikembangkan kembali dalam hal desain atau penambahan database sesuai kebutuhan pengolahan data Aplikasi Sistem Informasi Akademik pada SD Integral Hidayatullah Depok.

3. Aplikasi Sistem Informasi Akademik perlu penambahan data yang lebih lengkap dan valid.

4. Aplikasi Sistem Informasi Akademik diharapkan dapat berkembang dan dimanfaatkan sebagaimana mestinya tanpa adanya penyalahgunaan pada informasi yang diberikan.

\section{DAFTAR PUSTAKA}

[1] A.S., R., \& Shalahuddin, M. (2015). Rekayasa Perangkat Lunak ( Terstruktur dan Berorientasi Objek) 2015. Informatika Bandung, 29.

[2] Adi widarma, R. S. (2016). JurTI-Adi Widarma.

[3] Dunne, J. P., \& Smith, R. P. (2010). PEMBUATAN SISTEM INFORMASI AKADEMIK SMP N 3 GODEAN MENGGUNAKAN JAVA DAN MYSQL. 21,
427-441.

[4] Hasugian, L. P., \& Novianti, E. (2015). Sistem Informasi Akademik Pada Sekolah Menengah Atas Negeri 4 Cimahi. 67-80. https://ojs.unikom.ac.id/index.php/jamika/art icle/view/650/467

[5] Indrajani. (2018). Database Design All In One. 7.

[6] Ingrid Rosalia Dewi, 2Rini Malfiany. (2017). Perancangan Sistem Informasi Administrasi Pembayaran Pada Sdit Lampu Iman Karawang Berbasis Visual Basic 6.0. Jurnal Interkom, 12(2), 4-12.

[7] Irawan, L. (2014). PERANCANGAN DAN PEMBUATAN SISTEM INFORMASI DATA SISWA DAN GURU SD NEGERI 1 DANGURAN. SSRN Electronic Journal, 5(564), 1-19. https://doi.org/10.4324/9781315853178

[8] Kuryanti, S. J. (2014). Perancangan Sistem Informasi Akademik Sekolah Berbasis Web Dengan Java. Jurnal Khatulistiwa Informatika, 2(1), 77-86. http://ejournal.bsi.ac.id/ejurnal/index.php/kh atulistiwa/article/view/1630/1187

[9] Ra, D. I., Thayyibah, A. T., \& Candi, B. (2020). Dewantara: Jurnal Ilmiah Pendidikan Islam Anak Usia Dini Volume 2 Nomor 1 Tahun 2020 e-ISSN: 26556332. 2, 2-5.

[10] Shiddiq, S., \& Pradnya D, W. M. (2013). Sistem Informasi Akademik Dan Administrasi Sdit Ar-Raihan Bantul. Data Manajemen Dan Teknologi Informasi (DASI), 14(4), 49. 